\title{
PATOFISIOLOGI TREMOR ISTIRAHAT PENYAKIT PARKINSON
}

\author{
Komang Agus Sukendar ${ }^{1}$, Sri Sutarni², Subagya ${ }^{2}$ \\ ${ }^{1}$ Residen Bagian Neurologi \\ ${ }^{2}$ Staf Senior Bagian Neurologi Fakultas Kedokteran Universitas Gadjah Mada/ \\ RSUP Dr. Sardjito
}

Korespondensi : bk_suken@yahoo.com

\begin{abstract}
ABSTRAK
Tremor merupakan salah satu gerakan involunter yang paling sering ditemukan. Tremor pada penyakit Parkinson menjadi gejala kardinal yang paling membingungkan antara lain karena terpisah dari bradikinesia dan rigiditas, dapat memberat pada sisi berlawanan dari sisi bradikinesia yang dominan (wrong-sided tremor), penanda penyakit yang benigna, tidak berhubungan dengan banyaknya defisiensi dopamin di substansia nigra, serta responsnya terhadap pengobatan dopamin tidak sebaik gejala lainnya. Model klasik lebih menekankan peranan ganglia basalis dalam memodulasi fungsi kortikal melalui sirkuit striato-thalamokortikal yang mengalami disfungsi dan menyebabkan bradikinesia serta rigiditas, namun tidak dapat menjelaskan tremor istirahat pada penyakit Parkinson.

Akan dikaji literatur tentang aspek patofisiologi tremor istirahat pada penyakit Parkinson. Tremor dapat disebabkan oleh adanya osilasi mekanik pada ekstremitas, refleks yang meningkat, osilasi sentral atau loop-feedback yang abnormal dalam sistem saraf pusat. Osilasi tremor dapat terjadi pada level membran neuronal, serta peningkatan eksitabilitas abnormal dan sinkronisasi pada ganglia basalis yang mempengaruhi koneksi thalamus dan kortikalnya.

Dasar-dasar patofisiologi serta berbagai model hipotesis dengan strukturstruktur yang terlibat telah dibuat untuk menjelaskan patofisiologi tremor Parkinson. Kebanyakan model dibuat berdasarkan perekaman yang detail pada sejumlah neuron yang terbatas misalnya preparat ex vivo, atau set bangunan yang terbatas misalnya perekaman elektrofisiologi. Kebanyakan model berfokus pada sebuah nodus pada sirkuit tunggal dan menginterpretasikan adanya perubahan pada sirkuit lainnya sebagai akibat sekunder. Model hipotesis finger-switchdimmer merupakan model hipotesis terbaru dan memberikan sebuah sudut pandang level sistem, di mana tremor Parkinson diinduksi oleh aktivitas ganglia basalis yang abnormal (finger), diproduksi oleh thalamus (switch), dan dimodulasi atau diperkuat oleh serebelum (dimmer). Model ini dapat memberikan penjelasan bagaimana sejumlah intervensi pada network ganglia basalis-thalamus dapat menghilangkan tremor.
\end{abstract}

Kata Kunci : tremor istirahat, penyakit Parkinson, patofisiologi. 


\title{
PATHOPHYSIOLOGY OF PARKINSON'S DISEASE RESTING TREMOR
}

\author{
Komang Agus Sukendar ${ }^{1}$, Sri Sutarni2 ${ }^{2}$, Subagya ${ }^{2}$ \\ ${ }^{1}$ Resident of Neurology Departement \\ ${ }^{2}$ Staf of Neurology Depart. Medical Faculty Universitas Gadjah Mada / Dr. \\ Sardjito Hospital \\ Correspondence : bk_suken@yahoo.com
}

\begin{abstract}
Tremor is one of the most common involuntary movement. Parkinsonian tremor became the most puzzling symptom because it apart from bradykinesia and rigidity, can worsen on opposite sides of bradykinesia (wrong-sided tremor), a marker of disease benign, not related to the number of dopamine deficiency in the substantia nigra, and the response to treatment of dopamine is not as good as that of other symptoms. Classic model emphasizes the role of the basal ganglia in modulating cortical functions via thalamo-striato-cortical circuit dysfunction causing bradykinesia and rigidity, but can not explain resting tremor in Parkinson's disease.

This review discuss resting tremor pathophysiology in Parkinson's disease. Tremor can be caused by mechanical oscillations of the extremities, increased reflexes, central oscillation or abnormal feedback loop in the central nervous system. Tremor oscillations can occur at the level of neuronal membranes, as well as an increase in abnormal excitability and synchronization in the basal ganglia and the thalamus that affects its cortical connections.

The pathophysiological basics and its various hypothetical model with involved structures have been made to explain the pathophysiology of Parkinsonian tremors. Most models are made by recording the details on a limited number of neurons eg ex vivo preparations, or set of buildings is limited eg electrophysiological recording. Most models focus on a single node in the circuit and interpret the changes in the other circuits as a secondary result. The finger-switch-dimmer hypothesis model is the latest hypothesis model and provide a viewpoint of the system level, where the tremors of Parkinson's induced by the abnormal activity of the basal ganglia (finger), produced by the thalamus (switch), and modulated or amplified by the cerebellum (dimmer). This model also provides an explanation of how a number of interventions on a network basal ganglia-thalamus can eliminate tremor.
\end{abstract}

Keywords : resting tremor, Parkinson's disease, pathophysiology. 


\section{PENDAHULUAN}

Tremor merupakan gerakan involunter yang paling sering ditemukan, di mana pada penyakit Parkinson menjadi gejala yang paling membingungkan antara lain karena terpisah dari bradikinesia dan rigiditas, dapat memberat pada sisi berlawanan dari sisi bradikinesia yang dominan (wrong-sided tremor), penanda penyakit yang benigna, tidak berhubungan dengan banyaknya defisiensi dopamin di substansia nigra, serta responsnya terhadap pengobatan dopamin tidak sebaik gejala lainnya. ${ }^{1}$ Model klasik lebih menekankan peranan ganglia basalis dalam memodulasi fungsi kortikal melalui sirkuit striato-thalamokortikal yang mengalami disfungsi dan menyebabkan bradikinesia serta rigiditas, namun tidak dapat menjelaskan tremor istirahat pada Parkinson. ${ }^{2}$ Tinjauan pustaka ini bertujuan untuk mengkaji literatur tentang aspek patofisiologi tremor istirahat pada penyakit Parkinson.

\section{TREMOR PENYAKIT PARKINSON}

Tremor adalah gerakan involunter ritmik, osilatorik yang dihasilkan dari kontraksi sinkron dan bergantian otot-otot antagonis yang diinervasi secara resiprokal. ${ }^{3}$ Observasi klinis mengarahkan 2 subtipe utama penyakit Parkinson yaitu tremor-dominan dan non-tremor dominan yang mencakup fenotip yang digambarkan sebagai sindrom akinetik-rigid dan postural instability and gait disorder (PIGD). Beberapa subgrup tambahan penyakit Parkinson memiliki gambaran fenotip campuran atau tidak diketahui dengan beberapa gejala motorik. ${ }^{4}$ Berikut ini akan dijabarkan mengenai patofisiologi tremor istirahat Parkinson.

\section{Patologi Tremor Parkinson}

Hallmark patologi penyakit Parkinson adalah degenerasi sel dopaminergik substansia nigra yang mengakibatkan deplesi dopamin pada striatum. Substansia nigra yang mengalami dampak lebih berat pada tremor-dominan adalah bagian medial khususnya area retrorubral A8, berbeda dengan area substansia nigra bagian lateral (A9) pada akinetikrigid.6,7 Hilangnya dopamin secara kronis mengubah anatomi dan fisiologi globus palidus eksternus (GPe) seperti pada striatum dan nukleus subthalamus (STN). Kemampuan pacemaker intrinsik neuron pallidal berkurang, kolateral intrapallidal menguat, dan koneksi subthalamo-pallidal juga menguat. Pada interaksi thalamus dengan ganglia basalis, eferen ganglia basalis membentuk synaps besar perisomatik GABAergik pada nukleus relai thalamus. Nukleus relai ini membentuk lingkaran berulang dengan korteks yang diyakini menghasilkan ritme otak osilatorik. Korteks dan relai thalamus mengirimkan kolateral ke thalamus retikular, kemudian memproyeksikan kembali ke relai thalamus. ${ }^{8}$

\section{Model Mekanisme Membran Pada Tremor}

Osilasi dapat terjadi pada level membran neuronal. ${ }^{5}$ Neuron thalamus mengekspresikan 4aminopyridine sensitive potassium currents, low threshold calcium currents, hyperpolarization-activated mixed cation currents, dan calciumdependent potassium current sehingga ketika kondisi elektrofisiologi tertentu tercapai, maka neuron thalamik sendiri dapat menimbulkan potensial aksi spontan. Potensial aksi pada neuron diikuti oleh hiperpolarisasi. 
Besarnya hiperpolarisasi cukup untuk membuat potensial membran di bawah -55 mV, de-inaktivasi 4aminopyridine sensitive potassium currents, low threshold calcium currents, hyperpolarization-activated cation currents, akibatnya terjadi cetusan rebound (post inhibitory rebound/PIR). Neuron-neuron thalamik inhibitorik resiprokal yang berpasangan mengalami sinkronisasi dan menimbulkan post-inhibitory rebound (PIR). Coupling pada banyak neuron menimbulkan sinkronisasi osilasi pada kelompok neuron, memungkinkan drive elektrikal yang cukup untuk menghasilkan dan mempertahankan tremor. ${ }^{5}$

\section{Dasar-dasar Patofisiologi Tremor Parkinson}

Tremor dapat disebabkan oleh adanya osilasi mekanik pada ekstremitas, refleks yang meningkat, osilasi sentral atau loop-feedback yang abnormal dalam sistem saraf pusat. ${ }^{7}$ Refleks hanya memainkan peran minor untuk pembentukan, mempertahankan dan modulasi tremor Parkinson klasik. Peranan generator sentral adalah jauh lebih penting. ${ }^{7}$

Salah satu peran utama sentral adalah adanya osilasi neuronal. Aktivitas osilatorik merupakan istilah non spesifik untuk mengindikasikan beberapa fungsi neural dapat berulang sendiri secara periodik. Hal ini dapat direfleksikan dalam cetusan unit tunggal atau local field potentials (LFP) yaitu representasi jumlah dari arus-arus transmembran lokal dan aktivitas sinaptik. ${ }^{8}$ Osilator sentral terdiri dari neuron otomatis sentral, yang secara otonom menimbulkan impuls pada frekuensi tertentu dan diselaraskan melalui koneksi interneuron, sedangkan hipotesis lainnya menyatakan osilator sentral merupakan sirkuit neuron di mana gelombang depolarisasi terjadi secara berulang, menghasilkan sinyal dengan frekuensi spesifik. ${ }^{9}$

Sinkronisasi

memainkan peranan penting berikutnya. Sinkron menunjukkan dua atau lebih kejadian yang terjadi hampir secara simultan. Local field potentials sendiri merepresentasikan fluktuasi potensial trans-membran yang terkoordinasi, dan oleh karena itu merupakan suatu sinkroni lokal. Pada kondisi fisiologi normal, ganglia basalis dan korteks motorik jarang tercetus secara sinkron. Setelah deplesi dopamin, osilasi unit tunggal pada GPi, GPe dan STN menjadi sangat sinkron satu sama lainnya. Terapi deep brain stimulation (DBS) dan kombinasi levodopa/agonis dopamin cenderung menurunkan sinkroni interneural. ${ }^{8}$

Proses patologik Parkinson

melibatkan hilangnya sel dopaminergik di substansia nigra pars kompakta (SNc), khususnya bagian lateral ventral. Hal ini menyebabkan deplesi dopamin pada striatum, khususnya pada putamen dorsolateral. Perubahan ini secara kuat berhubungan dengan bradikinesia, namun relevansinya pada tremor istirahat masih tidak jelas. ${ }^{10}$ Studi menggunakan imaging [1231] FP-CIT SPECT menunjukkan tremor istirahat tidak berhubungan dengan deplesi dopamin nigrostriatal namun berhubungan dengan deplesi dopamin pallidum. ${ }^{11}$

Studi juga menunjukkan adanya sirkuit ganda pada tremor Parkinson. Analisis magnetoensefalografi menunjukkan network serebelo-diensefalik-kortikal berhubungan dengan tremor istirahat. ${ }^{1}$ Sirkuit striato-thalamokortikal dan serebelo-thalamokortikal saling terintegrasi. Pada model ini, baik striatum maupun serebelum mempengaruhi korteks serebri melalui sirkuit yang paralel maupun komplementer, dengan kedua struktur tersebut juga 
memodulasi satu sama lainnya pada level subkortikal. ${ }^{2}$

\section{Model Hipotesis Tremor Parkinson}

Beberapa model hipotesis telah dibuat untuk menjelaskan tremor istirahat pada penyakit Parkinson. Hipotesis thalamic pacemaker dibuat berdasarkan temuan in vitro pada neuron thalamus guinea pig bahwa properti intrinsik biofisikal neuron thalamus dapat memungkinkannya bertindak sebagai sistem relai dan sebagai osilator sel tunggal pada dua frekuensi yang berbeda, yaitu 9-10 dan 5-6 Hz. Sel thalamus yang sedikit terdepolarisasi cenderung berosilasi pada $10 \mathrm{~Hz}$, sedangkan sel yang hiperpolarisasi berosilasi pada $6 \mathrm{~Hz}$. Kedua frekuensi ini koinsiden dengan frekuensi dari tremor fisiologis (pada sel yang sedikit terdepolarisasi) dan tremor penyakit Parkinson (pada sel yang hiperpolarisasi). Asumsi kunci model ini adalah neuron thalamus (tunggal), bukan sirkuit ganglia basal, membentuk pacemaker tremor. Hipotesis thalamic filter juga berdasarkan data in vitro dan mengajukan bahwa tremor istirahat Parkinson muncul jika osilasi frekuensi tinggi $(12-15 \mathrm{~Hz})$ pada ganglia basalis diubah (filter) menjadi pola 4-6 Hz oleh neuron thalamik VL anterior. Gambaran kunci bahwa pacemaker tremor utamanya berlokasi di ganglia basalis (pallidum), dengan interaksi pallidothalamik menentukan frekuensi akhir tremor. Hipotesis STN-GPe pacemaker berdasarkan data in vitro dan mengajukan STN dan GPe tergabung sebagai pacemaker yang dimodulasi oleh inhibisi striatal pada neuron GPe. Hipotesis loss-ofsegregation berdasarkan temuan pada primata normal bahwa aktivitas neuron-neuron pallidal tidak saling berhubungan satu sama lain (tersegregasi), namun pada primata dengan Parkinson terjadi peningkatan signifikan pada hubungan antara neuron pallidal yang berjauhan sehingga menyebabkan hilangnya segregasi. Hal ini dapat menyebabkan sinkronisasi berlebihan pada ganglia basalis, kemungkinan karena kolateral inhibitorik pallidum dipengaruhi oleh deplesi dopamin menyebabkan tremor. Gambaran kunci bahwa sirkuit ganglia basalis, bukan thalamus, membentuk pacemaker tremor.7,11

Helmich et al. mengkonstruksikan sebuah model yang bertujuan untuk menspesifikasi dan mengintegrasikan peranan kedua sirkuit striato-thalamokortikal dan serebelo-thalamokortikal pada tremor, menggunakan MRI fungsional untuk mengidentifikasi respons serebral yang berfluktuasi dengan variasi spontan pada amplitudo tremor, yang diukur dengan EMG pada saat scanning. Berdasarkan data-data yang didapat dibuatlah sebuah model yaitu: aktivitas di ganglia basalis, memicu (trigger) respons yang berhubungan dengan tremor pada sirkuit serebelo-thalamo-kortikal, yang menghasilkan tremor. Model hipotesis ini dinamakan hipotesis dimmer-switch. ${ }^{11}$

\section{Pembaharuan Model Hipotesis}

Hipotesis terbaru dari Duval et al. mengajukan pembaharuan dengan model hipotesis finger-switchdimmer. Pada model ini, tremor diinduksi oleh aktivitas ganglia basalis patologik (sebagai finger), dihasilkan oleh perubahan pada aktivitas thalamus (sebagai switch), dan dimodulasi oleh aktivitas serebelar (sebagai dimmer). ${ }^{12}$

Struktur kunci pada hipotesis ini adalah thalamus. Hal tersebut berdasarkan dari pengamatan menggunakan laser displacement sensor pada saat sebelum, selama 
dan seminggu setelah dilakukan operasi stereotaktik fungsional. Bukti bahwa thalamus merupakan sentral dari tremor Parkinson, berasal dari adanya dampak yang jelas dari pembuatan lesi pada sebuah nukleus thalamus spesifik, yaitu nukleus ventral lateral bagian posterior (VLp) atau nukleus ventral intermediate (VIM), tergantung dari nomenklatur yang digunakan. ${ }^{12}$

Neuron thalamus memiliki
kemampuan frekuensi tremor, ketika terdapat modulasi pada eksitabilitas thalamus melalui hiperpolarisasi atau penurunan impuls eksitatorik. Pada Parkinson, proyeksi GABA inhibitorik ke thalamus menjadi masif, dan menginduksi penurunan aktivitas thalamo-kortikal. Hal ini menyebabkan aktivitas bursting ritmik pada frekuensi tremor dalam thalamus. Studi model komputerisasi menunjukkan aktivitas bursting ritmik pada GPi juga meningkatkan kemungkinan terjadinya aktivitas bursting ritmik pada neuron thalamus. Hal ini mengindikasikan bahwa tidak hanya perubahan firing rate pada GPi, namun juga perubahan firing pattern dapat menimbulkan aktivitas bursting ritmik pada thalamus. ${ }^{12}$

Network di antara nukleusnukleus thalamik dengan kemampuan nukleus retikular untuk merelai dan meningkatkan aktivitas bursting pada thalamus, dapat meningkatkan osilasi tremor melalui sirkuit multipel sampai pada titik tertentu dicapai untuk dapat mengkonsolidasi tremor. Neuron thalamus retikular memiliki proyeksi inhibitorik kuat ke neuron thalamokortikal yang bertanggung jawab untuk merelai informasi ke area korteks yang sesuai. Neuron thalamo-kortikal tersebut juga mengirimkan kolateral eksitatorik ke neuron retikular, yang memperkuat aktivitas inhibitorik neuron retikular ke neuron output thalamo-kortikal. Terdapat loop resiprokal inhibitorik dan eksitatorik yang melibatkan nukleus retikular dan neuron thalamo-kortikal. Neuron thalamokortikal dapat menunjukkan respons post inhibitory rebound yang kuat. Input inhibitorik yang kuat dari nukleus retikular dapat menghasilkan potensial aksi rebound burst. Sinkronisasi thalamik secara luas dimungkinkan oleh neuron relai inhibitorik dan eksitatorik yang konvergen dan divergen dalam thalamus. Nukleus thalamus memiliki proyeksi resiprokal dengan korteks serebri. Burst firing diamplifikasi pada regio kortikal, dan osilasi tremor pada area kortikal terkunci dalam waktu yang sama dengan tremor perifer. Aktivitas kortikal yang berhubungan dengan tremor dapat memberikan umpan balik ke thalamus melalui jalur kortiko-thalamik yang mengaktivasi neuron nukleus thalamus retikular inhibitorik. Hal ini dapat menguatkan atau mensinkronkan bursting ritmik dalam thalamus. ${ }^{12}$

Peran serebelum pada tremor Parkinson adalah untuk memastikan agar properti osilatorik seperti frekuensi atau amplitudo stabil. Pemutusan feedback sensorik melalui rhizotomi dorsal tidak akan menghilangkan tremor, namun sebaliknya akan menyebabkan amplitudo dan frekuensi yang bervariasi. Fenomena ini terjadi karena rhizotomi dorsal mencegah serebelum untuk memainkan perannya dalam usaha menstabilisasi tremor. Pasien dengan hemiserebelektomi masih tetap menunjukkan tremor setelah intervensi tersebut namun variabilitas tremornya meningkat. Serebelum memodulasi properti dari tremor Parkinson, sama seperti peranannya dalam memodulasi gerakan volunter. ${ }^{12}$ 


\section{DISKUSI}

Telah dijelaskan bagaimana dasar-dasar patofisiologi dan berbagai model hipotesis tremor Parkinson. Adanya keterbatasan pada model patofisiologi yang ada telah mendorong dikembangkannya model-model yang lebih baru.

Diketahui bahwa pola low threshold calsium spike burst terdapat pada pasien Parkinson tremordominan maupun akinetik, dan pada model hipotesis thalamic pacemaker, didapatkan burst tidak koheren dengan perekaman tremor di perifer. Pasien Parkinson tremor-dominan menunjukkan karakteristik tremorlocked burst yang berbeda tanpa low threshold calsium spike burst, pada nukleus thalamus ventrolateral (VL) posterior namun tidak pada VL anterior. Temuan ini dapat dianggap menunjukkan bahwa low threshold calsium spike burst yang patologis kemungkinan tidak berhubungan dengan tremor. Alternatif lain, low threshold calsium spike burst thalamus dapat diubah menjadi tremor-locked burst oleh adanya properti re-entry dari sirkuit thalamokortikal.7,11

Stimulasi pada pallidum dengan frekuensi tinggi, tidak menyebar ke korteks motorik. Hal ini membuat kecil kemungkinan osilasi frekuensi tinggi pada ganglia basalis menghasilkan tremor seperti yang diajukan pada hipotesis thalamic filter Banyak yang menghubungkan peningkatan osilasi frekuensi tinggi (8-35 Hz) di ganglia basalis pada pasien Parkinson dengan akinesia namun tidak untuk tremor.7,11 Hipotesis STN-GPe pacemaker yang mengajukan bahwa pacemaker ini bertanggung jawab untuk aktivitas osilatorik yang tersinkronisasi pada ganglia basalis normal dan patologik, ternyata didapatkan osilasi tersebut terjadi pada frekuensi antara $0,4-1,8$ $\mathrm{Hz}$, dan tidak jelas apakah mereka memiliki hubungan dengan tremor Parkinson akibat kurangnya pengamatan pada in vivo.7,11 Pada hipotesis loss-of-segregation, adanya koherensi yang inkonsisten antara osilasi ganglia basalis dan tremor, mengurangi kemungkinan adanya hubungan kausal diantara fenomena ini. 7,11

Hipotesis dimmer-switch dari Helmich et al. memberikan sebuah aspek baru dengan menawarkan mekanisme yang menjelaskan bagaimana ganglia basalis dan sirkuit serebelo-thalamo-kortikal saling berinteraksi. Dengan adanya penekanan pada kombinasi kontribusi ganglia basalis yang memicu/trigger tremor posisi on/offset, dianalogikan sebagai light switch, dan kontribusi serebelothalamo-kortikal yang memodulasi intensitas tremor, dianalogikan sebagai light dimmer. Model ini mengkombinasikan beberapa gambaran dari hipotesis-hipotesis sebelumnya menjadi sebuah penjabaran framework yang lebih besar. ${ }^{11}$

Hipotesis finger-switch-dimmer merupakan hipotesis terbaru yang merupakan penyempurnaan dari hipotesis sebelumnya. Model baru ini dibuat berdasarkan fakta bahwa thalamus sangat sensitif terhadap osilasi. Tindakan thalamotomi nukleus VL tidak akan mempengaruhi gerakan volunter, akan memungkinkan perubahan neuroplastik pada proprioseptif, namun juga tidak akan memungkinkan tremor menjadi reemerge pasca operasi. Jaringan yang terinterkoneksi multipel pada otak memungkinkan terjadinya pemulihan penuh fungsi motorik dan propioseptif, namun tidak pada tremor. Fakta utama ini meyakinkan thalamus adalah episenter proses produksi tremor Parkinson. Kesuksesan thalamotomi yang terukur secara tepat, terletak pada 
fakta bahwa target langsung sel tremor Parkinson, menginterupsi setiap kemungkinan untuk mentransmisikan osilasi tersebut ke struktur otak lainnya, yang menyebabkan switchnya rusak atau tidak berfungsi. Peran serebelum tidak berpartisipasi menyebabkan tremor melalui sirkuit serebelothalamo-kortikal seperti yang diajukan oleh Helmich et al. namun untuk mempertahankan fungsi normalnya dan membandingkan duplikat eferen dari gerakan volunter alternating berupa tremor dengan informasi sensorik yang datang dari perifer. ${ }^{12}$

Deep brain stimulation (DBS) atau operasi stereotaktik pada struktur target lain selain thalamus efektif mengurangi tremor. Pallidotomi atau subthalamotomi telah menunjukkan pengurangan tremor, mencegah induksi aktivitas bursting thalamus melalui penurunan aktivitas inhibitorik GPi. Pengurangan signifikan pada aktivitas inhibitorik ke thalamus akan menyebabkan perbaikan tremor karena akan mencegah induksi aktivitas bursting ritmik dalam thalamus (finger telah dihilangkan dari switch). Stimulasi STN dapat menyebabkan inhibisi indirek pada aktivitas GPi patologik, yang akan "menormalkan" output motorik ganglia basalis. Dalam hal ini, stimulasi STN juga akan mengurangi kemungkinan menginduksi aktivitas bursting sel thalamus, sehingga menghilangkan finger dari switch. Model ini dapat memberikan penjelasan bagaimana sejumlah intervensi pada network ganglia basalis-thalamus dapat menghilangkan tremor. Intervensi DBS pada GPi dan STN mengurangi tremor dengan menghilangkan induksinya, sedangkan DBS pada thalamus mengurangi tremor dengan secara langsung menghilangkan produksinya dari osilator sentral. ${ }^{12}$
Model patofisiologi terus berkembang seiring dengan temuan bukti-bukti baru yang ada. Di masa mendatang, adanya kemungkinan ditemukannya efektivitas DBS pada struktur target lainnya dalam mengurangi tremor Parkinson, akan memberikan peluang untuk semakin memperbaharui pemahaman kita tentang patofisiologi tremor penyakit Parkinson.

\section{KESIMPULAN}

Osilasi tremor dapat terjadi pada level membran neuronal, serta peningkatan eksitabilitas abnormal dan sinkronisasi pada ganglia basalis yang mempengaruhi koneksi thalamus dan kortikalnya. Model hipotesis finger-switch-dimmer memberikan sebuah sudut pandang level sistem yang dapat mengintergrasikan aktivitas ganglia basalis, thalamus serta serebelum. Model ini dapat memberikan penjelasan bagaimana sejumlah intervensi pada network ganglia basalis-thalamus dapat menghilangkan tremor.

\section{DAFTAR PUSTAKA}

1. Hallett M. Parkinson's disease tremor: pathophysiology. Parkinsonism and Related Disorders. 2012;18S1:S85-S86.

2. Lewis MM, Du G, Sen $\mathrm{S}$ et al. Differential involvement of striato- and cerebello-thalamocortical pathways in tremor- and akinetic/rigid-predominant parkinson's disease. Neuroscience. 2011;177:230239.

3. Puschmann A, Wszolek, ZK. Diagnosis and Treatment of Common Forms of Tremor. Semin Neurol 2011;31(1):65-77.

4. Lewis SJ, Foltynie T, Blackwell $\mathrm{AD}$ et al. Heterogeneity of Parkinson's disease in the early clinical stages using a data driven 
approach. J Neurol Neurosurg Psychiatry 2005;76:343-8.

5. Shaikh AG, Optican LM, Zee DS. Membrane mechanism of tremor, in: Mechanism and Emerging Therapies in Tremor Disorders. Contemporary Clinical

Neuroscience, Springer;2013.

6. Jellinger KA. Post mortem studies in Parkinson's disease - is it possible to detect brain areas for specific symptoms? J Neural Transm 1999;56(Suppl):1-29.

7. Deuschl G, Raethjen J, Baron R et al. The pathophysiology of parkinsonian tremor: a review. $J$ Neurol 2000;247[Suppl 5]:V33V48.

8. Ellens DJ, Leventhal DK. Electrophysiology of Basal Ganglia and Cortex in Models of Parkinson Disease. J Parkinsons Dis 2013;3(3):241-254.

9. Bartolic A, Pirtosek Z, Rozman J et al. Tremor amplitude and tremor frequency variability in Parkinson's disease is dependent on activity and synchronisation of central oscillators in basal ganglia. Medical Hypotheses 2010;74:362-365.

10. Oroz R, Jahanshahi M, Krack P et al. Initial clinical manifestations of Parkinson's disease: features and pathophysiological mechanisms. Lancet Neurol 2009;8:1128-39.

11. Helmich RC, Hallett M, Deuschl $\mathrm{G}$ et al. Cerebral causes and consequences of parkinsonian resting tremor: a tale of two circuits? Brain 2012;135:32063226.

12. Duval C, Daneault JF, Hutchison WD, Sadikot AF. A brain network model explaining tremor in Parkinson's disease. Neurobiology of Disease 2015;85:49-59. 
